\title{
OPTIMASI PENGGUNAAN PIPERAZINE DALAM CAMPURAN MDEA PADA PROSES ABSORPSI GAS ALAM
}

\author{
Rispiandi ${ }^{1, *}$, Saripudin ${ }^{1}$ \\ ${ }^{1}$ Jurusan Teknik Kimia Politeknik Negeri Bandung, Jl. Gegerkalong Hilir Ciwaruga Bandung Barat \\ *E-mail: rispiandi@gmail.com
}

\begin{abstract}
ABSTRAK
Gas $\mathrm{CO}_{2}$ adalah gas asam dan merupakan kontaminan utama yang terkandung pada gas alam yang harus dihilangkan untuk menghindari masalah pada proses pemanfaatannya. Jika bercampur dengan air, gas $\mathrm{CO}_{2}$ akan membentuk senyawa asam yang korosif yang merusak sistem perpipaan, mengurangi kapasitas perpipaan dan akan membeku di dalam pipa pada temperatur rendah. Dewasa ini pelarut MDEA paling banyak digunakan pada absorpsi $\mathrm{CO}_{2}$ dari gas alam karena tidak korosif dan lebih ramah terhadap lingkungan. Namun begitu, untuk meningkatkan daya serap MDEA terhadap $\mathrm{CO}_{2}$ diperlukan zat aktivator yaitu Piperazine. Piperazin berfungsi sebagai katalis yang mempercepat absorbsi $\mathrm{CO}_{2}$ dengan MDEA dimana mekanisme kerjanya adalah dengan mengubah $\mathrm{CO}_{2}$ fasa gas menjadi fasa liquid sehingga mudah larut dalam MDEA. Penelitian ini terdiri dari tiga tahap yaitu validasi model menggunakan data design dan data proses, analisa sensitivitas (simulasi), serta penentuan kondisi optimum beberapa variabel proses. Dari penelitian dihasilkan bahwa konsentrasi piperazin paling optimal adalah $2 \%$ massa (MDEA).
\end{abstract}

Kata kunci: Gas $\mathrm{CO}_{2}$, absorpsi, MDEA, piperazine, simulasi

\begin{abstract}
$\mathrm{CO}_{2}$ gas is an acid gas and is the main contaminant in natural gas which must be removed to avoid problems in the utilization process. When mixed with water, $\mathrm{CO}_{2}$ gas will form corrosive acid compounds that damage the piping system, reduce the capacity of the piping, and will freeze in the pipe at low temperatures. Currently, MDEA is a non-corrosive and environmentally friendly solvent for $\mathrm{CO}_{2}$ absorption from natural gas. However, to increase the absorption of MDEA to $\mathrm{CO}_{2}$, an activator substance, namely Piperazine, is needed. Piperazine functions as a catalyst that accelerates the absorption of $\mathrm{CO}_{2}$ with MDEA where its mechanism of action is to convert gaseous $\mathrm{CO}_{2}$ into a liquid phase so that it is easily soluble in MDEA. This research consists of three stages, namely model validation using design data and process data, sensitivity analysis (simulation), and determining the optimum conditions for several process variables. From the research, it was found that the most optimal concentration of piperazine was $2 \%$ by mass (MDEA).
\end{abstract}

Keywords: $\mathrm{CO}_{2}$ gas, absorption, MDEA, piperazine, simulation

\section{PENDAHULUAN}

Keberadaan gas alam di Indonesia cukup strategis setelah peran minyak sebagai sumber energi utama mulai berkurang. Penggunaan gas alam ditunjang cadangan yang cukup besar yaitu 152,89 TSCF (Rezky, 2013) dengan reserve to production $(\mathrm{R} / \mathrm{P})$ mencapai 59 tahun (ESDM, 2008). Komponen utama gas alam adalah metana $\left(\mathrm{CH}_{4}\right)$ yang merupakan hidrokarbon dengan rantai terpendek dan teringan. Gas alam juga mengandung hidrokarbon yang lebih berat seperti etana $\left(\mathrm{C}_{2} \mathrm{H}_{6}\right)$, propana $\left(\mathrm{C}_{3} \mathrm{H}_{8}\right)$ dan butana $\left(\mathrm{C}_{4} \mathrm{H}_{10}\right)$. Selain kandungan utama tersebut, gas alam yang keluar dari sumur gas membawa 
senyawa-senyawa pengotor antara lain gas $\mathrm{CO}_{2}$.

Gas $\mathrm{CO}_{2}$ adalah gas asam dan merupakan kontaminan utama terkandung pada gas alam. Nilai kandungan $\mathrm{CO}_{2}$ yang tinggi pada lapangan gas memberikan tantangan tersendiri dalam mengembangkan gas alam secara komersial. Gas alam dengan kadar $\mathrm{CO}_{2}$ sangat tidak disukai karena kapasitas kalori gas alam akan turun sehingga menjadi bahan pertimbangan dari sisi pengembangan lapangan gas secara komersial jangka panjang, Gas $\mathrm{CO}_{2}$ merupakan pengotor yang harus dihilangkan untuk menghindari masalah pada proses pemanfaatannya (Bonnytha, 2009)

Dewasa ini pelarut MDEA paling banyak digunakan pada absorpsi $\mathrm{CO}_{2}$ dari gas alam, dengan alasan sifatnya tidak korosif dan lebih ramah terhadap lingkungan. Namun begitu, untuk meningkatkan daya serap MDEA terhadap $\mathrm{CO}_{2}$ diperlukan zat aktivator yaitu Piperazine.

Absorbsi $\mathrm{CO}_{2}$ tanpa akivator berjalan lebih lambat. Piperazin berfungsi sebagai katalis yang mempercepat absorbsi $\mathrm{CO}_{2}$ dengan MDEA dimana mekanisme kerjanya adalah dengan mengubah $\mathrm{CO}_{2}$ fasa gas menjadi fasa liquid sehingga mudah larut dalam MDEA. Jika konsentrasinya terlalu sedikit, maka proses absorpsi $\mathrm{CO}_{2}$ berjalan lambat sehingga konentrasi $\mathrm{CO}_{2}$ pada sweet gas menjadi lebih besar.

Pemurnian gas dilakukan untuk menghilangkan pengotor yang tidak diinginkan didalam gas bumi sebelum dikirimkan ke konsumen. Tujuan dari pemurnian gas tersebut adalah untuk meningkatkan kualitas dari gas bumi dan menurunkan bahaya pada sistem proses \& perpipaan. Komposisi dari gas bumi merupakan faktor yang mempengaruhi proses pemurnian gas yang akan dilakukan. Pada umumnya, proses pemurnian gas yang dilakukan adalah gas sweetening $\left(\mathrm{CO}_{2}\right.$ removal) dan gas dehydration, Christensen, Dan Laudal. 2009

Kehadiran gas $\mathrm{CO}_{2}$ bersamaan dengan air akan memberikan efek korosif terhadap material yang dilaluinya. Material baja karbon biasanya digunakan pada pipa produksi minyak dan gas alam dengan kadar gas $\mathrm{CO}_{2}$ sampai dengan $40 \% \mathrm{CO}_{2}$ akan mengalami laju korosi yang sangat tinggi. Gas ini dapat menyebabkan kerusakan berbahaya dan fatal bagi infrastruktur pipa produksi dan pengolahan gas alam. Kebocoran pipa akibat efek korosi pada fasilitas pengolahan gas alam akan menyebakan kerusakan dan bencana yang mahal dari sisi keselamatan kerja dan komersial

Gas sweetening bertujuan untuk menurunkan kadar $\mathrm{CO}_{2}$ dan $\mathrm{H}_{2} \mathrm{~S}$ dalam raw gas yang dapat mengganggu pada proses selanjutnya. $\mathrm{CO}_{2}$ dapat membeku pada suhu rendah sehingga dapat menyumbat peralatan dan perpipaan. Selain itu, $\mathrm{CO}_{2}$ tidak memiliki nilai bakar sehingga menurunkan nilai bakar (heating value) dari gas bumi. $\mathrm{H}_{2} \mathrm{~S}$ merupakan gas beracun yang sangat korosif sehingga dapat menyebabkan korosi pada peralatan proses dan sistem perpipaan (Muhammad Fauzi, 2009).

Unit $\mathrm{CO}_{2}$ removal didisain untuk menurunkan kadar $\mathrm{CO}_{2}$ dengan kapasitas 200 MMSCFD (sour gas) dari konsentrasi $23 \%$ mol menjadi $5 \%$. Namun, kondisi aktual $\mathrm{CO}_{2}$ di feed gas sebesar 22,89\% dengan laju gas sebesar 54,26 MMSCFD (Data rata $\mathrm{CO}_{2}$ Removal Plant Subang Daily Report Operation, 1 Maret-14 Maret 2012).

Untuk mencapai tujuan tersebut, gas alam yang mengandung $\mathrm{CO}_{2}$ tinggi di 
kontakkan dengan MDEA di kolom Absorber pada kondisi operasi suhu rendah (melepaskan panas atau eksoterm) dan tekanan tinggi. Sehingga didapatkan gas alam yang miskin $\mathrm{CO}_{2}$ (sweet gas) dan amine yang kaya $\mathrm{CO}_{2}$ (rich amine).

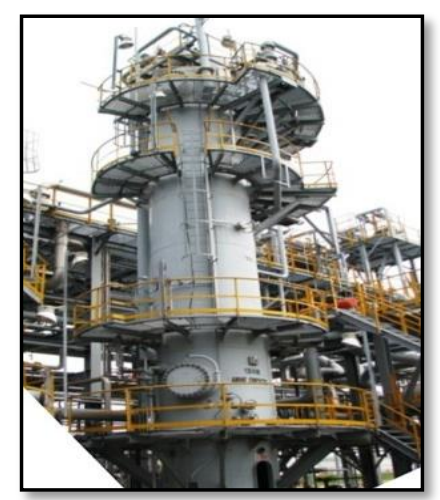

Gambar 1. Amine Contactor Hess (IndonesiaPangkah) Limited

Methyldiethanolamine (MDEA)

adalah cairan kuning jernih, tidak berwarna atau pucat dengan bau amonia. Zat ini larut dengan air, alkohol dan benzena. Methyl diethanolamine juga dikenal sebagai $\mathrm{N}$-metil dietanolamin dengan rumus kimia $\mathrm{CH}_{3} \mathrm{~N}\left(\mathrm{C}_{2} \mathrm{H}_{4} \mathrm{OH}\right)_{2}$.

Absorbsi $\mathrm{CO}_{2}$ tanpa akifator berjalan lebih lambat, Untuk menghasilkan $\mathrm{HCO}_{3}$ dan $\mathrm{MDEAH}^{+}$membutuhkan $1 \mathrm{~mol} \mathrm{CO} \mathrm{CO}_{2}$, 1 mol MDEA dan 1 mol $\mathrm{H}_{2} \mathrm{O}$. Untuk meningkatkan daya serap MDEA terhadap $\mathrm{CO}_{2}$ diperlukan zat aktivator yaitu Piperazine.

Piperazine selektif terhadap $\mathrm{CO}_{2}$. Sistem aktifator berperilaku seperti katalis, yang mempercepat absorbsi $\mathrm{CO}_{2}$ dengan aMDEA. Hal ini karena sifat dari piperazine yang dapat mengubah $\mathrm{CO}_{2}$ fasa gas menjadi fasa liquid. Komponen sistem aktifator juga dapat diregenerasi secara kontinyu

\section{METODOLOGI PENELITIAN}

Penelitian ini diawali dengan penyusunan literatur dari beberapa jurnal ilmiah yang sesuai. Pembuatan model dikaji lebih dahulu dengan mempertajam pemahaman fundamental prosesnya. Berikut langkahlangkah penelitian yang dikerjakan:

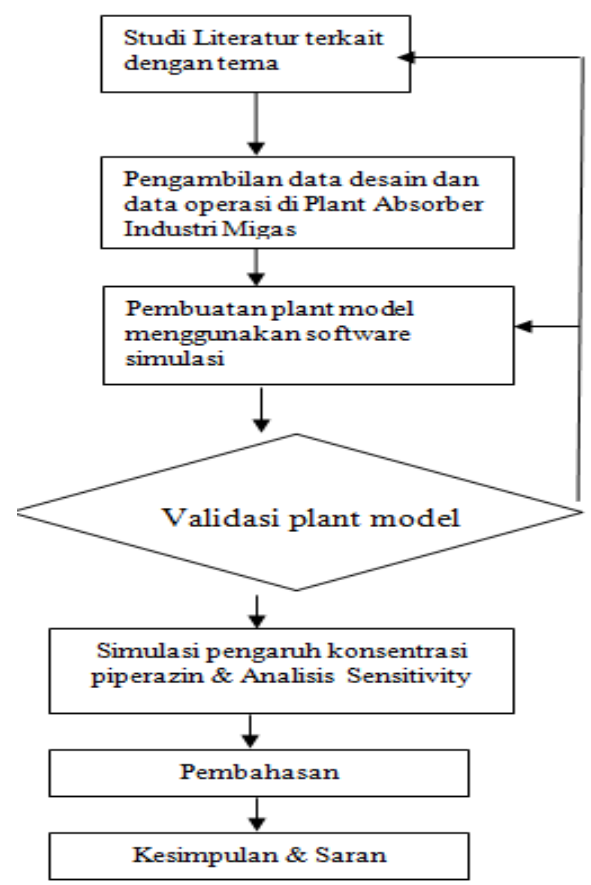

Gambar 2. Skema pelaksanaan penelitian Manipuated variable : \% Piperazine

Process variable: kandungan $\mathrm{CO}_{2}$ di sweet gas

\section{HASIL DAN PEMBAHASAN}

\section{Validasi Model Simulasi}

Pada tahap persiapan ini dilakukan validasi simulasi dari keseluruhan plant di PT Rekayasa Industri Subang. Ditentukan pula titik validasi yang nantinya akan dibandingkan dengan data aktual di lapangan dan eror yang dihasilkan haruslah dibawah $10 \%$. Titik validasi yang ditinjau disajikan pada Gambar 3. 


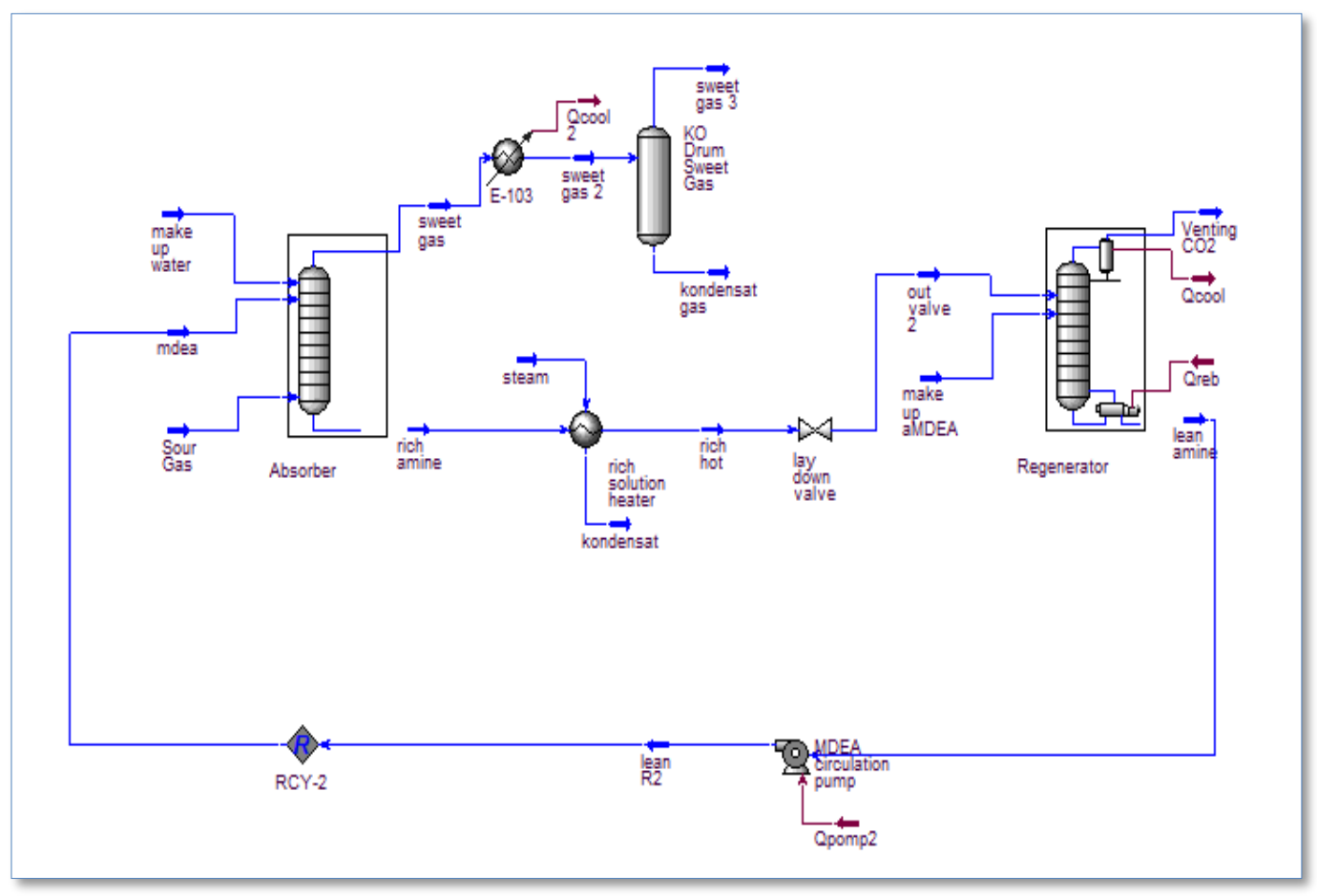

Gambar 3. Titik Validasi Simulasi Overall $\mathrm{CO}_{2}$ Removal Plant

Pada proses validasi ini kondisi operasi pada setiap alatnya diatur sesuai dengan hasil dari pengambilan data di lapangan. Untuk data feed gas adalah temperatur $=53^{\circ} \mathrm{C}$, tekanan $512 \mathrm{psig}$, dan flow 54 MMSCFD. Sedangkan data aMDEA (3\% piperazin) yaitu temperatur $75^{\circ} \mathrm{C}$, tekanan 512 psig, dan flow 800 USGPM dengan komposisi $40 \%$ volume. Berdasarkan hasil yang diperoleh dari simulasi HYSYS ini, dihasilkan penyimpangan seperti yang ditampilkan pada Tabel 1.

\section{Tabel 1 Titik Validasi di Aliran Sweet Gas}

\begin{tabular}{ccccc}
\hline Parameter & $\begin{array}{c}\text { Keadaan } \\
\text { disain }^{(1)}\end{array}$ & $\begin{array}{c}\text { Keadaan }_{\text {aktual }^{(2)}} \\
\text { Fraksi }\end{array}$ & $\begin{array}{c}\text { Hasil } \\
\text { simulasi }\end{array}$ & $\begin{array}{c}\text { Eror } \\
(\%)\end{array}$ \\
\hline $\begin{array}{c}\mathrm{CO}_{2} \\
\text { Fraksi }\end{array}$ & 0,8258 & 0,03614 & 0,0394 & 8.3 \\
Metana & 0,8189 & 0,892 & 8.2 \\
\hline Sumber: & & & &
\end{tabular}

(1) P\&ID Over All $\mathrm{CO}_{2}$ Removal Plant PT Rekayasa Industri Subang

(2) Data rata-rata Gas Chromatografi $\mathrm{CO}_{2}$ Removal Plant Subang, 1 Maret-14 Maret 2012
Hasil simulasi menunjukkan error $<10$ $\%$, sehingga hasil simulasi dianggap valid dan dapat dilanjutkan optimasi konsentrasi piperazin. Konsentrasi piperazin di variasi dari 1 sampai 5 persen berat aMDEA :

Tabel 2 Titik Validasi variasi konsentrasi

Piperizine terhadap \% $\mathrm{CO} 2$

\begin{tabular}{cc}
\hline \% Piperazin & \% CO2 dalam sweet gas \\
\hline 0.5 & 4 \\
1 & 3.93 \\
2 & 3.89 \\
3 & 3.94 \\
4 & Not converge \\
5 & Not converge
\end{tabular}

Keterangan:

Not coverage: Hasil simulasi tidan mengarah ke satu harga

Dari hasil simulasi dapat diketahui bahwa persen piperazin paling optimal adalah $2 \%$, memiliki kandungan $\% \mathrm{CO}_{2}$ di sweet gas paling kecil, dengan error $8,2 \%$. Piperazin berfungsi sebagai katalis yang mempercepat absorbsi $\mathrm{CO}_{2}$ dengan MDEA dimana mekanisme kerjanya 
adalah dengan mengubah $\mathrm{CO}_{2}$ fasa gas menjadi fasa liquid sehingga mudah larut dalam MDEA. Jika konsentrasinya terlalu sedikit, maka proses absorpsi $\mathrm{CO}_{2}$ berjalan lambat sehingga konentrasi $\mathrm{CO}_{2}$ pada sweet gas menjadi lebih besar. Jika konsentrasi piperazin terlalu besar, maka dengan sendirinya akan mengurangi konsentrasi MDEA sehingga proses absorpsi $\mathrm{CO}_{2}$ juga berjalan lambat.

Hasil penelitian pembanding (Donius, Akmal Fuadi, 2017) hasil penelitian Studi Absorbsi CO2 dalam Larutan MDEA-TEA dengan Katalis Piperazine

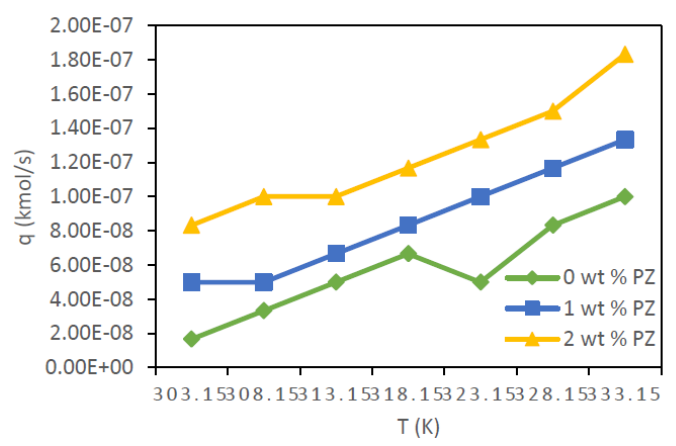

Pengaruh kenaikan temperatur terhadap laju absorpsi $\mathrm{CO}_{2}$ dalam larutan MDEA TEA 40\% berat dengan variasi $\%$ berat promotor piperazine pada laju alir pelarut 200 $\mathrm{mL} /$ menit.

Pada temperatur $323.15 \mathrm{~K}$, laju absorpsi $\mathrm{CO}_{2}$ ketika hanya menggunakan larutan MDEA-TEA (tanpa piperazine) adalah sebesar 1.67 x 10-8 kmol/det, ketika ditambahkan $1 \%$ berat piperazine adalah sebesar 5 x 10-8 kmol/det dan ketika ditambahkan $2 \%$ berat piperazine adalah sebesar 8.3 x 10-8 kmol/det. Penambahan promotor piperazine kedalam larutan MDEA dapat meningkatkan laju absorpsi $\mathrm{CO}_{2}$ secara signifikan.

\section{KESIMPULAN}

Dari penelitian ini, dapat disimpulkan bahwa simulasi berhasil dibangun dan divalidasi dengan error 8,2\%. Dari hasil simulasi dapat diketahui bahwa persen piperazin paling optimal adalah 2\% massa (MDEA).

\section{DAFTAR PUSTAKA}

Anggraeni, Nur Rita dan Rizky Imanda. 2012. Laporan Kerja Praktik Pertamina EP Field Prabumulih. Bandung : Jurusan Teknik Kimia POLBAN

Anonim. 2008. Prinsip Pemrosesan Gas Alam. From http://shcommunity.wordpress.co $\mathrm{m} / 2008 / 10 / 25 /$ prisippemrosesan-gas-alam/, 15 Mei $\underline{2012}$

Bonnytha. 2009. Proses Dehidrasi pada Pemurnian Gas. From http://infosharingbonnytha.blogspot.com/2009/05/ dalam-proses-pengolahan-gasalam.html, 15 Mei 2012

Christensen, Dan Laudal. 2009. Gas Dehydration. Aalborg University Esbjerg (AAUE): Denmark.

Bahan Ajar Kimia Fisika, 2012

Buku Pintar Migas Indonesia. Amine Unit $\mathrm{H}_{2} \mathrm{~S} / \mathrm{CO}_{2}$ Absorption Unit \& Amine Regeneration Unit

Donius, Akmal Fuadi, 2017. Studi Absorbsi CO2 dalam Larutan MDEA-TEA dengan Katalis Piperazine. Fakultas Teknologi Industri, ITS

Geankoplis, Christie John. 2003. Transport Process And Separation Process Principles. USA: Pearson Prentice Hall

Juanda, Tolage. Laporan Kuliah Kerja Profesi Energy Equity Epic Sengkang Pty.Ltd

Lutfi, Ahmad dan Juanan Rosul. 2012. Laporan Kerja Praktik di Hess (Indonesia-Pangkah) Limited. Bandung : Jurusan Teknik Kimia POLBAN

Marsella,Vera dan Yulia Maharani. 2012. Laporan Kerja Praktik di $\mathrm{CO}_{2}$ 
Removal Plant PT. Rekayasa Industri-Pertamina EP Field Subang. Bandung : Jurusan Teknik Kimia POLBAN

Patria, Harry Simulasi, Optimasi, dan kajian ekonomi pemurnian sour gas dengan absorbsi campuran amina pada gas sweetening plant

PE_324_Lecture_7_NG_Sweetening_Pr ocess.pdf 